\title{
A New Jerusalem
}

\author{
Michael Takeo Magruder \\ Artist and Researcher \\ UK \\ m@takeo.org
}

\begin{abstract}
A New Jerusalem is an interactive and immersive virtual reality installation that seeks to embody the spirit of the new Jerusalem as described in the Book of Revelation. The artwork manifests as a beautiful and illuminated metropolis that is based upon Revelation's architectural descriptions, and is generated in real-time using Unity3D and Flash. The installation is experienced through two distinct perspectives as witnessed and related by the Book's narrator, John the Seer: an external 'projected' view of the city descending from heaven and an internal 'personal' view of the city witnessed through an Oculus Rift VR headset.
\end{abstract}

Contemporary Art, Computational Art, Virtual Reality Art, Theology, Real-time 3D environment, Oculus Rift experience

\section{ABOUT THE ARTWORK}

The narrative of the Book of Revelation is not just one of apocalyptic destruction; it is also a journey of salvation and unveiling. The Book's positive culmination is expressed in the creation of a heavenly city - referred to as New Jerusalem - that arises from the remains of the old world.

A New Jerusalem is an immersive virtual reality installation that seeks to embody the spirit of this prophesised city. The artwork manifests as a beautiful and illuminated metropolis that is based upon Revelation's architectural descriptions, and can be experienced through two distinct perspectives as witnessed and related by the Book's narrator, John the Seer.

Unlike other pictorial visualisations of this biblical prophecy that have been created throughout history, the underlying structure of $A$ New Jerusalem is generated solely from the text of Revelation itself that has been translated into a data code form and rendered in four-dimensional virtual space (XYZ plus time). However, the imagined cityscape is also constructed using current Google Maps data of present day Jerusalem, thus offering the possibility that - in the words of theologian Professor Edward Adams "the new creation is not a wholly unrecognisable place, even if the new Jerusalem is like no city the world has ever seen". Within this context, the artwork asks viewers to contemplate why we should care about our present society and environment if promises of "a new heaven and a new earth" (Rev 21.1) await us.

\section{ONLINE DOCUMENTATION}

www.takeo.org/nspace/2014-dta-new-ierusalem/

\section{TECHNICAL DESCRIPTION}

A New Jerusalem is constructed with: two highspecification computer systems capable of realtime high definition 3D rendering (Unity3D); an Oculus Rift DK2 virtual reality headset; a singlechannel high definition video projection system; and a 2.1 audio system (Flash).

The installation is modular and can be configured to fit in many types of spaces and environments. The artwork consists of two viewpoints of the imagined city. The first is an external view using the projection system and the second is an internal view using the Oculus Rift headset. An algorithmic Flash soundscape completes the environment.

\section{ACKNOWLEDGEMENTS}

A New Jerusalem was produced in collaboration with Drew Baker (Unity3D programming) and Prof. Edward Adams (academic context). The artwork was created in 2014 as part of De/coding the Apocalypse - a solo exhibition exploring contemporary creative visions inspired by and based on the Book of Revelation; presented by the Cultural Institute at King's College London in partnership with contemporary art center MOSTYN and the Department of Theology \& Religious Studies at King's. The artwork's research phase (2012-13) was funded by the Leverhulme Trust's artist-in-residence program. 

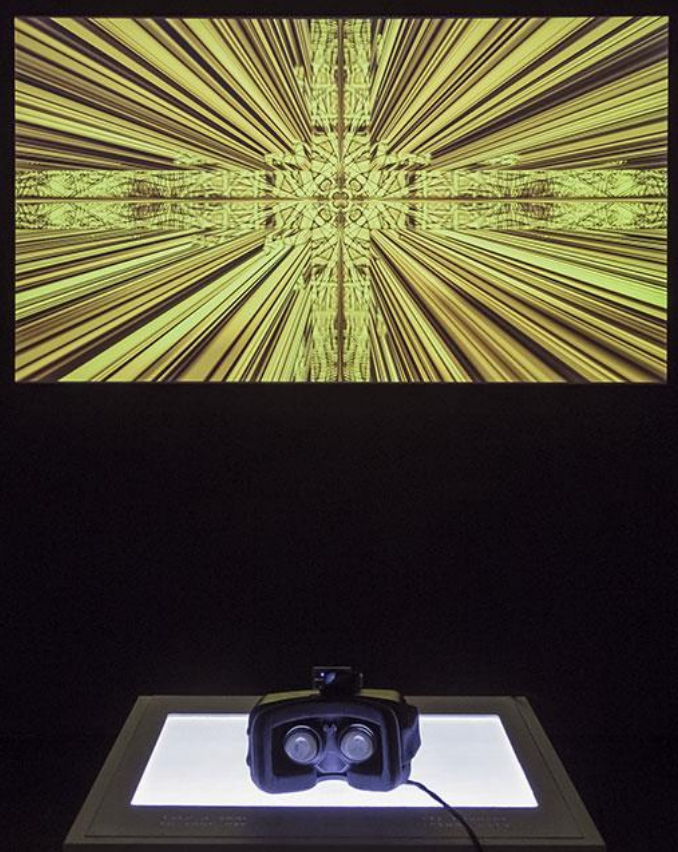

Figure 1: Michael Takeo Magruder, A New Jerusalem, modular installation with Oculus Rift VR headset, single channel HD projection, computers and sound system, 2014. Installation as part of De/coding the Apocalypse, solo exhibition, Inigo Rooms, Somerset House, London, UK, 2014. (photograph by Jana Chiellino).

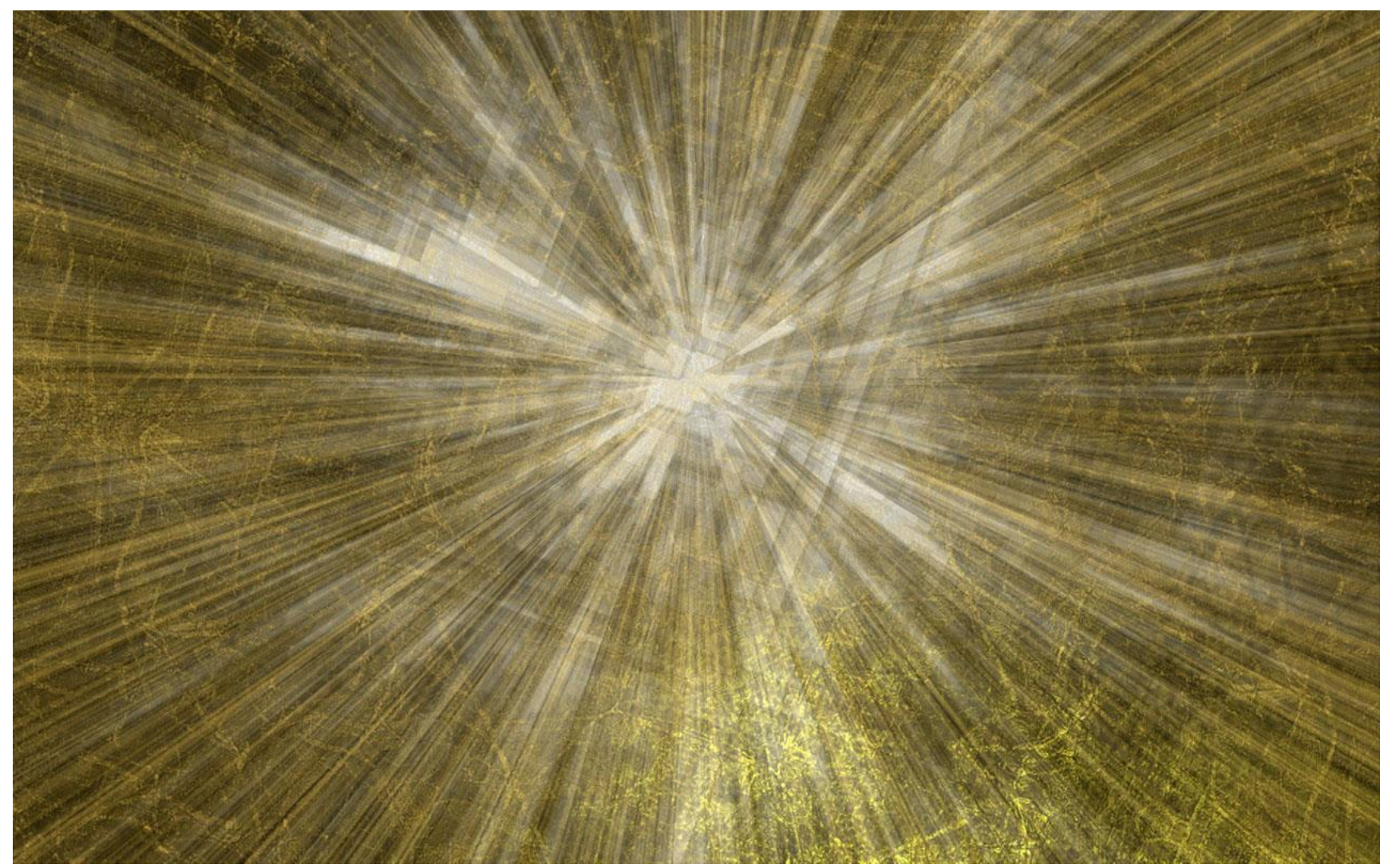

Figure 2: Michael Takeo Magruder, A New Jerusalem, real-time 3D virtual environment (Unity3D) and algorithmic soundscape (Flash), 2014. Still image of an internal view of the city as seen through the Oculus Rift heads. 